\title{
CONFLICTOS EN ÁFRICA: EL CASO DE LA REGIÓN DE LOS GRANDES LAGOS Y DE SUDÁN
}

\author{
Mbuyi Kabunda \\ Profesor de Relaciones Internacionales y Estudios Africanos (GEA/UAM) \\ Director del Observatorio de Estudios sobre la Realidad Social del África Subsahariana (FCA/UAM) \\ Universidad Autónoma de Madrid
}

\section{RESUMEN}

Los conflictos africanos tienen cada uno su especificidad e idiosincracia, pero encontrando todos un denominador común en las luchas manipuladas entre las nacionalidades, por una parte, y los nacionalismos estatales, por otra, y últimamente por el afán por el acceso a los recursos naturales. En los casos particulares de los Grandes Lagos, abordados en el presente análisis, es preciso subrayar que los conflictos nacen de la instauración de un «etnicismo científico» (Jean-Pierre Chrétien), junto a la desaparición del aparato del Estado en la RDC dando lugar a un saqueo de recursos naturales en este país, y en Sudán fundamentalmente de las desigualdades de toda índole entre el centro y las periferias de este país (el Sur de Sudán y el Darfur). La solución en ambos casos pasa por la creación de Estados de derecho (el fin de la cultura de la impunidad) y la descentralización (federalismo).

Palabras clave: Grandes Lagos, RDC, Sudán, Darfur, recursos naturales, saqueo, desigualdades, guerrillas.

\begin{abstract}
The African conflicts have each one his specificity and idiosyncrasy, but finding all a common denominator in the fights manipulated between the nationalities, on one hand, and the state nationalisms, for other one, and lately for the zeal for the access to the natural resources. In the particular cases of the Great Lakes, approached in the present analysis, it is necessary to underline that the conflicts are born of the restoration of one «scientific ethnicism» (Jean-Pierre Chrétien), close to the disappearance of the device of the State in the DRC giving place to a plunder of natural resources in this country, and in Sudan fundamentally of the inequalities of any nature between the center and the peripheries of this country (Southern Sudan and Darfur). The solution in both cases happens for the Democracies' creation (the end of the culture of the impunity) and the decentralization (federalism).
\end{abstract}

Key words: Great Lakes, DRC, Sudan, Darfur, natural resources, plunder, inequalities, guerrilla warfares. 


\section{RÉSUMÉ}

Les conflits africains ont chacun sa spécificité et idiosyncrasie, mais ayant tous un dénominateur commun autour des luttes instrumentalisées entre les différentes nationalités, d'une part, et les nationalismes étatiques, d'autre part, et dernièrement à cause de l'archarnement pour l'accès aux ressources naturelles. Dans les cas particuliers de la région des Grands Lacs, objet de la présente analyse, il faut aussi souligner que les conflits naissent de l'instauration d'un «ethnicisme scientifique» (Jean-Pierre Chrétien), à laquelle s'ajoute la disparution de l'appareil de l'État en RDCongo, donnant lieu à un pillage systématique des ressources naturelles dans ce pays, et au Soudan fondamentalement à cause des inégalités de tout acabit entre le centre et les périphéries de ce pays (le Sud du Soudan et le Darfour). La solution, dans ces cas d'espèce, passe par l'instauration d'États de droit (la fin de la culture de l'impunité) et la décentralisation (fédéralisme)

Mots clés: Grands Lacs, RDC, Soudan, Darfour, ressources naturelles, pillage, inégalités, guérillas.

\section{Introducción}

Las guerras civiles que han tenido como escenario el continente africano, en el período que se extiende desde 1960 hasta el momento actual, se han cobrado la vida de más de 10 millones de personas con un balance de 7 millones de refugiados y 20 millones de desplazados internos. Es decir, el equivalente de un holocausto en cuanto al número de vidas perdidas.

Para limitarse sólo a los más significativos, analizados por Copson (1994) y Zartman (1990), y que van desde las guerras de descolonización y las nacidas de la guerra fría, pasando por las guerras de secesión o irredentistas e interestatales, hasta las guerras civiles con carácter económico o fomentadas desde el exterior (cf. Nguyen, 2010: 19-26; Nagan, 2002: 75-77), se puede mencionar: en el África Occidental, las guerras de Liberia, Sierra Leona, Guinea Bissau, y Costa de Marfil; en el África Central, las de la región de los Grandes Lagos (Ruanda, Burundi, Uganda, la República Democrática del Congo - RDC - , Chad, Congo-Brazzaville y Centroáfrica; en el cuerno de África, las de Sudán —entre el norte y sur y en el Darfur-, Etiopía y Eritrea, Somalia; y en el África Austral, las de Angola y Mozambique. Lo que da la imagen de un continente violento, pese a la tendencia actual a la reducción de estos conflictos.

¿Pero cuales son las verdaderas causas de estos conflictos? ¿Por qué llegan a tomar los conflictos africanos proporciones tan preocupantes generando «una de las mayores calamidades de nuestra época»? ¿Cuáles son los principales protagonistas de estas contiendas y sus motivaciones, declaradas o latentes?

El presente análisis pretende dar respuestas a estas preguntas tomando como casos de estudio dos de los conflictos de la «diagonal de la muerte o del vacío», que va desde Angola pasando por la RDC hasta Sudán. Nos limitaremos a estos dos últimos por razón de espacio y por seguir aún activos con ramificaciones en otros países. Es decir, en la región de los Grandes Lagos, en torno a las guerras de la RDC, y de Sudán, en su dimensión norte-sur y del actual conflicto del Darfur y su extensión en Chad y en Centroáfrica.

\section{Causas de los conflictos africanos: más allá del etnicismo y de la codicia}

En África las principales causas de los conflictos, - que no pueden atribuirse exclusivamente a las lealtades históricas de los africanos o a sus genes (definición patológica o 
racista de los africanos considerados como predispuestos a los suicidios colectivos y a la violencia), a la pobreza o el subdesarrollo (enfoque paternalista) o a los factores económicos (enfoque economista que pasa por alto los aspectos políticos) - , obedecen también a un conjunto de factores multidimensionales: históricos y actuales, estructurales y coyunturales, internos y externos entremezclados entre ellos.

Al igual que los conflictos que se desarrollan en las otras regiones del mundo, y siguiendo a Suganami (citado por Ramsbotham et al -2011: 193; véase también a Kabunda, 1997: 71-81), las guerras en África también tienen «causas profundas o históricas, causas intermedias y causas desencadenantes».

En la línea de este planteamiento, y de una manera concreta, los conflictos africanos se originan en el carácter no acabado del Estado, tanto a nivel interno como a nivel internacional (Zartman, 1990), en particular en la ruptura entre el Estado y la nación. Dicho con otras palabras, se trata de un Estado nacionalmente mal integrado cuya soberanía, más externa que interna, no suele acompañarse de la legitimidad sociológica.

Existen, pues, causas generales y específicas que explican estos conflictos, y que se podría resumir de la manera siguiente:

a) las luchas para la consolidación del poder o la confiscación del mismo por un grupo determinado, tras el proceso de descolonización,

b) el carácter arbitrario y artificial de las fronteras, y por lo tanto fuentes de las disputas,

c) las rivalidades entre los Estados para la hegemonía regional, apoyando los movimientos rebeldes contra los gobiernos de los países vecinos,

d) el incremento de la exportación de armas hacia el continente,

e) la negación del carácter multiétnico o multinacional del Estado africano por los gobiernos centrales ${ }^{1}$,

f) el desarrollo desigual o la modernización diferencial, práctica heredada de la colonización y profundizada por las élites poscoloniales;

g) la personalización o confiscación del poder por un grupo social, étnico o confesional, dando lugar a la gestión étnica del Estado (etnocracia o etnonacionalismo),

h) la manipulación de los integrismos étnicos y confesionales por los dirigentes por fines políticos o económicos en el período de democratización,

i) las luchas por el control de los recursos naturales en la post guerra fría ${ }^{2}$, tanto por los actores locales como regionales e internacionales.

En definitiva, un análisis profundo de los conflictos en África ha de tomar en cuenta aspectos multidimensionales, que Kofi Annan resumió acertadamente en su informe dirigido en abril de 1998 al Consejo de Seguridad de las Naciones Unidas sobre «las causas del conflicto y la promoción de la paz duradera y el desarrollo sostenido en África», específicamente los legados históricos tales como la creación y/o fortalecimiento de las consciencias étnicas por la colonización (cf. Rothchild (1997), los factores internos y externos, las motivaciones económicas, el desequilibrio entre el espacio vital y la superpoblación, en ciertas zonas, y las tensiones en las formas de entender la sociedad y el Estado en otras.

De igual modo, queremos dejar constancia de la evidencia según la cual sin ser causas exclusivas en los conflictos africanos, como sostienen las teorías de las «nuevas guerras»,

1 Los gobiernos africanos suelen rechazar, según Owona (1985; véase también Rothchild, 1997) cualquier tipo de federalismo o particularismo para fortalecer el poder y control del Estado o con la excusa de preservar la estabilidad política y la integridad territorial, heredada de la colonización.

2 En esta época de la globalización neoliberal, en la opinión de Braeckman (2009a), han surgido importantes rivalidades por el control de los recursos naturales al alcance sólo del mejor armado y agresivo, y del más rápido. 
los recursos naturales son determinantes en su mantenimiento y prolongación al permitir la compra de armas, la financiación de ejércitos o bandas armadas y el control de territorios y poblaciones. Es decir, son combustibles que avivan los conflictos, tal y como se ha comprobado en los países ricos en recursos naturales como Liberia, Sierra Leona, Angola o la RDC.

En estos países, los conflictos políticos nacidos de la instrumentalización de las luchas internas por las élites para el acceso al poder o para su confiscación, han evolucionado en guerras con carácter socioeconómico por el control de los diamantes, el petróleo, el cobre, el cobalto, el coltán, etc., cuya comercialización, junto a la droga y al tráfico de armas, permite a las facciones armadas financiar sus actividades bélicas o sus esfuerzos de guerra (cf. Misser y Vallée, 1997), e incluso para honrar los contratos firmados con los grupos industriales occidentales o las multinacionales, que se han aprovechado del caos para tener acceso a las materias primas a precio de saldo, mediante la colaboración con los señores de la guerra haciendo caso omiso de la violación de los derechos humanos. De este modo, los principales protagonistas alimentan sus cuentas privadas para así seguir con el sistema neopatrimonial.

En el mismo orden de ideas, Klare puntualiza que «tanto en Angola como en Sierra Leona, así como en otros lugares afectados por los conflictos similares, es evidente que los grandes consorcios dedicados a la explotación de recursos contribuyen a la violencia endémica por cuanto compran a los beligerantes los diamantes, los minerales, la madera y demás materiales de valor» (2003: 237; véase también Hirsch, 2001: 25), financiando de este modo a los movimientos rebeldes dotados así con medios para seguir con la guerra.

Las torpes políticas de desarrollo impuestas desde el exterior tienen una gran responsabilidad en el estallido de estos conflictos al fomentar las tensiones locales, al crear una situación en la que hay poco ganadores y muchos perdedores y al debilitar la capacidad del Estado en la gestión de conflictos, Estado incapaz de controlar sus fronteras e implicado cada vez más en el tráfico de toda índole, a través de sus agentes, e incluso amenazado de implosión.

El caso de Ruanda es también ilustrativo al respecto: la Agencia norteamericana para la cooperación internacional, el Banco Mundial y el FMI recomendaron en la década de los 80 el cultivo del café a los campesinos ruandeses. Sin, embargo, perdieron de vista algunas nociones básicas de economía, pues fomentaron dicho cultivo en otros países, latinoamericanos y asiáticos, con los consiguientes excedentes en los mercados internacionales y caída de los precios. Lo mismo puede decirse del estaño, principal producto minero de este país, cuyo precio cayó a la mitad en 1989 como consecuencia de los productos de sustitución en el Norte (cf. Uwizeyimana, 2005). El resultado fue el empobrecimiento de miles de agricultores ruandeses y el debilitamiento del Estado. Las crisis sociales se dispararon, y explican en parte el genocidio de 1994, al pasar los ingresos procedentes del café de 144 millones de dólares en 1985 a 30 millones en 1993, agudizando las tensiones políticas y económicas que hicieron perder al Estado el control sobre su población y territorio. O según Périès y Servenay (2007: 230-235), que abundan en el mismo sentido, son las consecuencias de las recetas neoliberales impuestas por el FMI y el Banco Mundial al gobierno ruandés de la época, en particular los programas de ajuste estructural (PAE) - la liberalización del comercio, la supresión de las subvenciones a los agricultores, la privatización del sector público y los recortes drásticos en los gastos públicos y sociales-, las que sirvieron de antesala al genocidio de 1994, junto al excesivo endeudamiento, la desviación de la ayuda al desarrollo para gastos militares, que aumentaron en un $274 \%$ entre 1989 y 1991 . Se generó así una verdadera «economía de guerra» con la ruina de miles de campesinos y la pauperización de amplias capas de la población a partir de octubre de 1990. 
Lo mismo puede decirse del cacao. La insistencia en las exportaciones, en el marco de los PAE, condujo a la sobreproducción mundial y al derrumbe de los precios. Esta situación alimentó los conflictos de Costa de Marfil donde la reducción de los ingresos nacionales, como consecuencia de dicho derrumbe, dio paso a las tensiones internas y a los sentimientos xenófobos hacia los «inmigrantes» con la ideología excluyente de la «ivoirité» o de la preferencia nacional en las décadas de los 90 y 2000.

Es verdad que el contexto de Guerra Fría ocultó, durante mucho tiempo, las lógicas económicas de las guerras africanas atribuidas a los únicos aspectos ideológicos, étnicos y confesionales o a los ideales políticos en detrimento de sus motivaciones económicas.

Hoy, en el marco del proceso de globalización, la guerra se ha convertido en un negocio para maximizar los beneficios a menor coste (armas ligeras, carne de cañón barato y contacto con las redes de la economía globalizada para la comercialización - Münkler, 2003-). Con la globalización, asistimos a la privatización de las guerras o de la violencia con el uso de las violaciones sexuales, consideradas como eficaces medios de limpieza étnica al permitir ahorrar los recursos y las municiones, y en definitiva humillar al otro grupo. Es la prolongación de la guerra por otros medios «baratos», tal y como sucedió en Ruanda y tal y como está sucediendo en la parte oriental de la RDC y en el Darfur.

\section{Los conflictos de la región de los Grandes Lagos: del genocidio de Ruanda al saqueo de los recursos naturales de la $\mathrm{RDC}$}

La región de los Grandes Lagos vive desde 1994 una tremenda crisis de la que apenas se está saliendo de ella. Esta región, en la intersección entre el África Central y el Âfrica Oriental, se caracteriza por una fuerte densidad de población (Burundi y Ruanda son los países más poblados del continente). Las montañas de las provincias del Kivu congoleño (Sur Kivu y Norte Kivu) acogen parte de este excedente de la población o sirven de territorio para su extensión.

La instrumentalización política de las tensiones interétnicas relacionadas con el problema agrario desde hace cinco décadas culminó con el genocidio de Ruanda en 1994, con un balance de 1 millón de muertos y más de 2 millones de refugiados en los Kivus (donde crearon un mini-Estado con su propia administración y sistema de financiación y de control), Acogiendo a estos refugiados en el territorio del Zaire (hoy RDC), el presidente Mobutu, internacionalmente aislado por sus prácticas dictatoriales, consiguió la rehabilitación por la comunidad internacional para evitar una catástrofe humanitaria.

Es preciso también recordar que los grupos armados de la región (como los movimientos rebeldes de Burundi, Ruanda, Uganda y RDC) siempre han utilizado y siguen utilizando el territorio de uno de los Estados como retaguardia en sus luchas contra los gobiernos establecidos. Y basta que haya ruptura del equilibrio en uno de estos países para que se produzcan repercusiones en otros (cf. Pourtier, 2004).

Las guerras de esta región, que tuvieron como epicentro el territorio de la RDC, pasaron por tres fases: la primera guerra tuvo lugar en 1996-1997 y fue inspirada por los países vecinos (Uganda, Ruanda, Burundi, Angola) contra el régimen de Mobutu; la segunda en 1998-2003, por algunos de estos países y sus aliados congoleños, contra el régimen de Kabila, y la tercera, de baja intensidad, se desarrolla exclusivamente en los Kivu desde 2004 hasta la actualidad (2011), con menos intensidad, y en torno fundamentalmente a los recursos naturales con la implicación de los actores locales, regionales e internacionales. Han tenido un balance de entre 5 y 6 millones de muertos. Es decir, la mayor tragedia humanitaria después de la Segunda Guerra Mundial. Pasamos a analizar brevemente estos conflictos. 


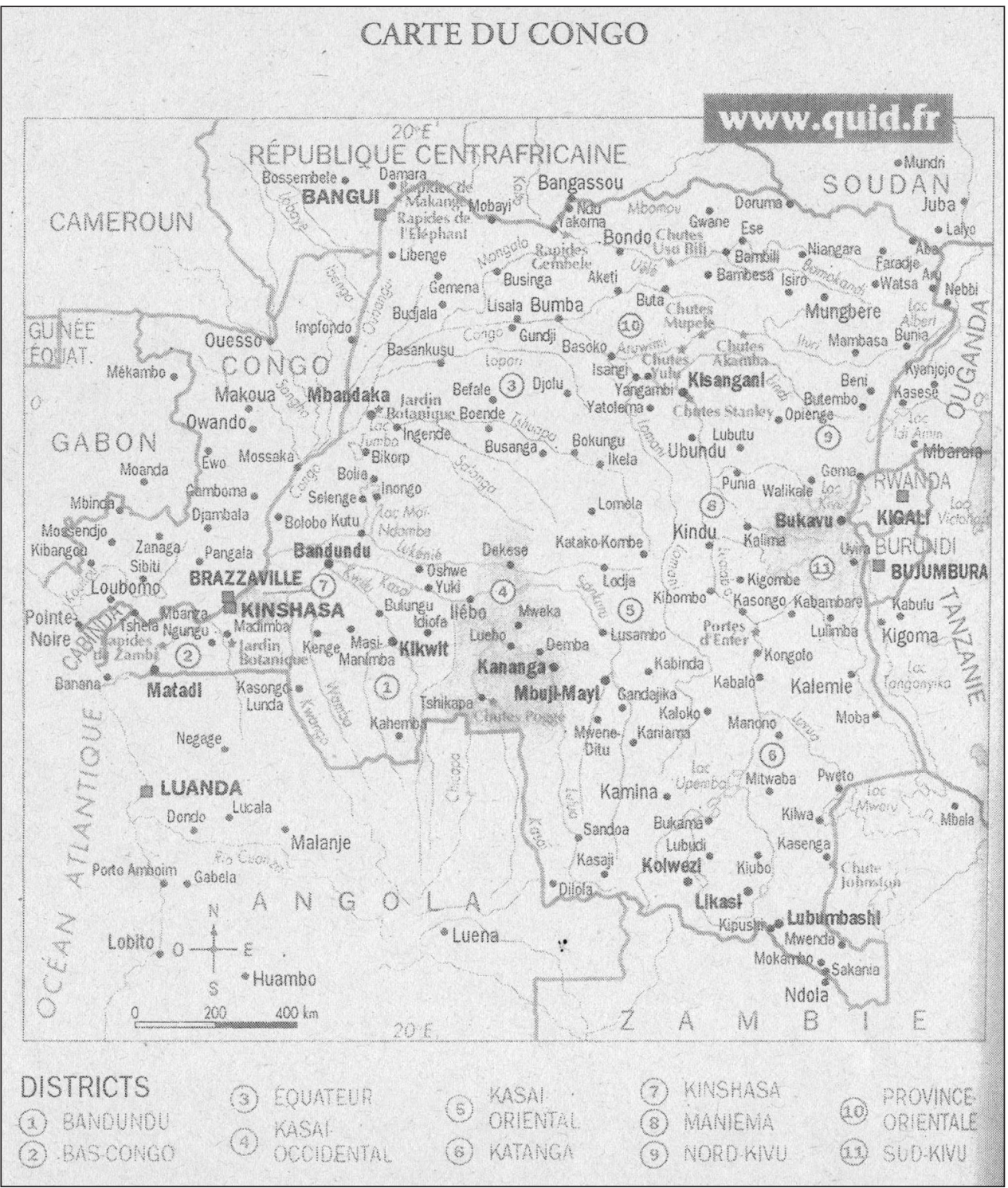

Figura 1. Mapa de la República Democrática del Congo.

Fuente: www.quid.com

\subsection{El genocidio de Ruanda de 1994 y sus ondas expansivas en la RDC}

Los extremistas hutus del entorno del presidente Juvénal Habyarimana se niegan a la aplicación de los acuerdos de Arusha (agosto de 1993) que prevén el reparto del poder con el Frente Patriótico Ruandés (FPR), integrado mayoritariamente por los refugiados tutsis, 
que atacaron en 1990 el norte de Ruanda a partir del territorio ugandés, en su intento de regresar a su país ante la negación de acogerlos por el gobierno de Habyarimana.

El 6 de abril de 1994, el atentado contra el presidente Habyarimana ${ }^{3}$ sirve de excusa a las matanzas, programadas y planificadas en todo el país de los tutsis y de los hutus de la oposición moderada, por los extremistas hutus, las milicias interahamwes del ex partido único (MRND) y los militares de las Fuerzas Armadas Ruandesas (FAR).

En el mismo momento, la guerrilla del FPR, bajo la batuta de Paul Kagamé, ataca a las FAR a partir de Uganda. Después de tres meses de combates, los rebeldes conquistaron Kigali y el conjunto del país, con la consiguiente caída del régimen hutu. El 17 de julio, la formación del gobierno de unión nacional consagra la victoria del FPR poniendo fin a las matanzas. Sin embargo, se produce una ola de refugiados (2 millones de hutus), infiltrados y liderados por el ejército y las milicias derrotados hacia los países vecinos, en particular en los campos de la RDC en los Kivus, que utilizaron como retaguardia para la reconquista del poder en Kigali, ante la indiferencia e incluso la complicidad del régimen de Mobutu, que organizó pogromos contra los tutsis zaireños de origen ruandés: los banyamulenges, instalados en el territorio zaireño desde hace varias décadas, y amenazados de expulsión hacia Ruanda.

\subsection{La primera guerra del Congo: 1996-1997 o la guerra de liberación contra la dicta- dura mobutista}

En octubre de 1996 estalla la rebelión de los banyamulenges, cuya nacionalidad está cuestionada por el gobierno zaireño, como queda subrayado. Reciben el apoyo militar de Ruanda, Uganda y Burundi. Junto a los demás opositores al presidente Mobutu, se agrupan en la Alianza de las Fuerzas Democráticas para la Liberación del Congo/Zaire (AFDL) liderada por Laurent-Désiré Kabila, un veterano guerrillero marxista-lumumbista contra el régimen de Mobutu. Entre octubre y diciembre, la AFDL destruye los campos de refugiados ruandeses infiltrados por las ex FAR y las milicias extremistas hutus, los interahamwes, responsables del genocidio de 1994, dando lugar a una nueva catástrofe humanitaria.

A comienzos de 1997, la guerra continúa sin ninguna resistencia de las Fuerzas Armadas Zaireñas (FAZ) con la caída una tras otra de las provincias zaireñas. En febrero, el Consejo de Seguridad de las Naciones Unidas pide el fin de las hostilidades y la retirada de «todas las fuerzas extranjeras, mercenarios incluidos». Sin embargo, los rebeldes controlan amplios territorios de Zaire con sus recursos minerales. Las mediaciones de Estados Unidos y de Sudáfrica para encontrar una transición pacífica fracasan. Kabila rechaza el alto el fuego y expresa su determinación a conquistar Kinshasa. En mayo de ese mismo año, el presidente Mobutu huye en exilio después de treinta años de poder dictatorial (y muere

3 En este atentado aéreo, no aclarado 18 años después de haber sucedido, fallecieron los presidentes de Ruanda (Juvénal Habyarimana) y Burundi (Cyprien Ntaryamira), ambos hutus. Se generó desde entonces hasta hoy en día una verdadera dicotomía político-jurídica en la comunidad internacional, en particular en Francia, en cuanto a los verdaderos autores de dicho atentado que desencadenó el genocidio de los tutsis y de los hutus moderados o de la oposición. Para unos, son los extremistas hutus del entorno de Habyarimana, descontentos de las «excesivas concesiones» hechas por el presidente a los tutsis en la cumbre de Arusha, los verdaderos responsables de dicho atentado, y subrayan la implicación de Francia por sus relaciones estrechas con el gobierno ruandés de la época y por no hacer nada para impedir el genocidio (o por intervenir tarde y de una manera interesada con la operación Turquesa); otros consideran al FPR de Paul Kagamé, el actual presidente de Ruanda, como el principal instigador del atentado en su «estrategia planificada», de provocar el genocidio de su propio grupo (tutsi) al inspirar el asesinato del presidente hutu. Utilizó la excusa del genocidio, y la consiguiente desestabilización del Estado, para acceder al poder y legitimarlo. Le acusan de cometer un acto de terrorismo internacional. Sobre el misterio de este atentado y toda la confusión político-jurídica, véanse a Onana (2005); Ayad (2008: 2-3); Del Ponte (2009: 119); Ayad y Bernard (2012: 22-23). 
en Rabat en septiembre), y Kabila se autoproclama presidente de Zaire, convertido en la RDC. El balance de esta guerra es de miles de muertos.

En resumen, esta primera guerra opone en el territorio zaireño un conglomerado de actores: el ejército del FPR (dominado por los tutsis) a los antiguos genocidas hutus (ex FAR y milicias interahamwes); el ejército de Burundi (de liderazgo tutsi) a los movimientos extremistas hutus burundeses; el ejército de Uganda y dos grupos rebeldes ugandeses, y algunos movimientos rebeldes zaireños liderados por la AFDL al gobierno de Mobutu.

\subsection{La segunda guerra del Congo (1998-2003) o la «primera guerra panafricana»}

En unos meses, las relaciones entre Kabila y sus antiguos aliados (ruandeses, ugandeses y burundeses), se deterioran por oponerse el nuevo mandatario a la dominación de los países vecinos y de los banyamulenges en el aparato del Estado.

Para los aliados de L. D. Kabila, el cambio de régimen en Kinshasa no significó el fin del uso del territorio congoleño por las ex FAR, los interahamwes, los grupos anti-Museveni y los grupos rebeldes hutus para atacar respectivamente a Ruanda, Uganda y Burundi. De ahí, la decisión de los presidentes de estos países de cambiar de nuevo el régimen de Kinshasa, contrariados por las manifestaciones de independencia y el ultranacionalismo de Kabila.

En agosto de 1998, estalló en el Kivu una nueva rebelión de los militares banyamulenges, decepcionados por el nuevo régimen de Kabila, que llevaron al poder en 1997. Recibieron el apoyo de Ruanda, Uganda y Burundi y desembocó en una guerra regional con la implicación de siete países y dos grandes coaliciones en el territorio congoleño: de un lado las tropas gubernamentales de Kabila, las milicias ruandesas interahamwes, las ex FAR y las milicias congoleñas mai-mai, apoyados por Angola, Zimbabue y más tarde Namibia y Chad; de otro, las facciones rebeldes congoleñas, rivales entre sí, apoyadas según las circunstancias y los intereses cambiantes por Ruanda, Uganda y Burundi. Kabila se salvó gracias a la intervención militar de Angola (para evitar el uso del territorio congoleño por la guerrilla de la UNITA), Zimbabue (interesado por las concesiones mineras y la recuperación del estatus de líder regional por Mugabe) y Namibia (por la alianza revolucionaria de los 60 y 70 entre Sam Nujoma, el presidente namibio, y Kabila).

Los combates se extienden en el territorio congoleño produciendo un inicio de partición del país: el gobierno sólo controla la mitad occidental, y el resto está en manos de los movimientos rebeldes congoleños. En agosto de 1999, se firmó en Lusaka un acuerdo de alto el fuego, que pidió a las fuerzas extranjeras retirar sus tropas y el desarme de las diferentes rebeliones del país. Para conseguir dicha meta, el Consejo de Seguridad creó la Misión de las Naciones Unidas en el Congo (MONUC) que con 17.600 cascos azules y un presupuesto de 1.000 millones de dólares, es la misión más costosa en el mundo. Sin embargo, los combates continuaron dando lugar a una confusión político-militar con el cambio de alianzas entre Ruanda y Uganda, cuyas tropas de ocupación se enfrentaron en la ciudad diamantífera congoleña de Kisangani en 1999, 2000 y 2002.

En enero de 2001 fue asesinado Laurent-Désiré Kabila, en condiciones no aclaradas, y le sustituyó como jefe de Estado su hijo, Joseph Kabila, que se mostró menos intransigente e instauró una colaboración con los Estados Unidos y los países vecinos, acusados o sospechados de ser implicados en el asesinato de su padre.

A finales de 2002, las tropas extranjeras se retiraron oficialmente de la RDC. Sin embargo, en la parte oriental se intensificaron los combates entre las facciones armadas rivales, avivados por Ruanda y Uganda que por guerrillas interpuestas, siguieron controlando los recursos naturales de esta parte del territorio congoleño. Este segundo conflicto calificado de la «primera guerra mundial africana», según la vicesecretaria de Estado norteamericana 
encargada de Asuntos africanos de la Administración Bill Clinton, Susan Rice, además de obedecer ampliamente al saqueo de los recursos naturales del Congo (Braeckman, 2009a; Nabudere, 2003; Naidoo, 2003), y de bloquear durante mucho tiempo el fin de la guerra, tuvo el balance de más de 4 millones de muertos.

En abril de 2003 se firmaron en Sun City (Sudáfrica) el protocolo del acta final del diálogo intercongoleño para restaurar la soberanía y la paz en la RDC. El presidente Joseph Kabila promulgó la Constitución de transición, que debería cerrarse con la celebración de las elecciones legislativas y presidenciales en julio de 2006, elecciones financiadas por la comunidad internacional a razón de 397 millones de dólares, las primeras celebras en el país después de 40 años.

La segunda vuelta de las elecciones, celebrada el 29 de octubre entre Joseph Kabila $(58,05 \%)$ y Jean-Pierre Bemba $(41,95 \%)$, dio la victoria al primero, que tuvo a su favor el negociar la paz y la retirada de las tropas extranjeras después de diez años de guerra. Ambos financiaron ampliamente su campaña electoral con el saqueo de los recursos naturales del país.

A pesar de celebrarse estas elecciones, siguieron los conflictos en las provincias orientales donde los movimientos de guerrillas, extranjeros y congoleños, se mantuvieron activos, haciendo difícil la rehabilitación del aparato del Estado.

Por todas esta razones, el Consejo de Seguridad decidió el 15 de mayo prorrogar hasta el 31 de diciembre de 2007 el mandato de la MONUC, convertida en MONUSCO (Misión de Observación y Estabilización de las Naciones Unidas en el Congo), con una nueva misión postelectoral de ayuda al gobierno congoleño en la instauración de la seguridad, en particular la protección de civiles, la seguridad del territorio, el desarme y la desmovilización de las «fuerzas negativas» o las procedentes de los países vecinos en las principales zonas de combates.

La guerra en la RDC es deseada y mantenida por los importantes beneficios que sacan de ella los principales protagonistas internacionales, regionales y nacionales, pues según recuerda Willame (2007), tanto en el Ituri como en el Kivu y en el norte de Katanga sigue la «economía de guerra» alimentada por la demanda de materias primas estratégicas, abundantes en la RDC (coltán, cobalto, oro, diamantes, madera...), una economía sobre la que la comunidad internacional sigue cerrando los ojos.

Según los sucesivos informes del Grupo de expertos de las Naciones Unidas (julio de 2001, noviembre de 2001 y octubre de 2002) sobre la explotación ilegal de los recursos naturales del Congo - véase también los informes de la ONG londinense Global Witness - , sobre las 85 empresas consideradas como teniendo actividades contrarias al código de conducta de las empresas multinacionales definido por la OCDE, en la RDC, se encuentra 4 grandes bancos (de los cuales 3 son belgas); 17 pequeñas empresas mineras (juniors miniers) norteamericanos, canadienses, belgas y británicas; 11 empresas diamantíferas belgas, así como varias decenas de empresas poco conocidas instauradas en África, Medio Oriente y Asia. Las elecciones de 2006, por las que apostó la comunidad internacional para resolver el problema de la legalidad del poder en la RDC, no resolvieron todos estos problemas de fondo.

\subsection{La tercera guerra del Congo o la guerra de Laurent Nkunda con el respaldo de Ruanda}

Los ataques de la ciudad de Bukavu en mayo-junio de 2004 y en diciembre de 2004 en los territorios de Masisi y de Rutshuru, por la guerrilla del CNDP (Congreso Nacional para la Defensa del Pueblo) dirigida por el general disidente tutsi, Laurent Nkunda, autoprocla- 
mado defensor de la comunidad tutsi del Kivu contra la «preparación del nuevo genocidio» a manos de los FDLR (Frente Democrático para la Liberación de Ruanda integrado por los rebeldes hutus ruandeses), y claramente apoyada por el gobierno ruandés. Posteriormente en noviembre de 2006, la guerrilla de Nkunda atacaba de nuevo la ciudad de Saké en el Kivu. Todos estos ataques o enfrentamientos se saldaron en su mayoría con la derrota de las tropas gubernamentales congoleñas, las FARDC (Fuerzas Armadas de la RDC), en parte por el embargo de armas decretado por la comunidad internacional desde hace una década contra la RDC, y no contra Ruanda.

Con estos episodios empezó de hecho la $3^{\text {a }}$ guerra, que al contrario de las dos anteriores guerras, se concentrará exclusivamente en los Kivus. Una zona, rica en minerales y oro, que en gran parte escapaba al control y autoridad del gobierno congoleño, y donde existían grupos paramilitares ugandeses y varias milicias hutus ruandesas refugiadas en ella desde el genocidio de 1994. Sin embargo, al igual que las dos guerras anteriores, los orígenes de este conflicto también se remontan a la crisis de Ruanda y al problema no resuelto (hasta ahora) de la «nacionalidad» de los ruandófonos (Kivu Norte) y de los banyamulenges (Kivu Sur). Tres eran los principales protagonistas de esta nueva guerra:

- Las FARDC desplegadas en el Kivu Norte desde octubre de 2007 para combatir a los rebeldes de Laurent Nkunda. Se trata de tropas generalmente mal pagadas y entrenadas, indisciplinadas, propensas al saqueo y responsables de la mayor parte de las violaciones de derechos humanos en dicha provincia, y que no pudieron acabar con la guerrilla de Nkunda. Muchos de sus jefes acuden a la parte oriental para enriquecerse, dedicándose más al tráfico de madera, droga y coltán que a defender el territorio congoleño y su población.

- El FDLR integrado por miembros de las ex FAR de los interahamwes o del Hutu Power, responsables del genocidio de 1994 en Ruanda, y de los jóvenes ruandeses reclutados en los campos de refugiados del Kivu, y unidos todos por el odio hacia los tutsis. Su principal objetivo es la reconquista del poder en Ruanda por las armas. Están presionados por sus jefes para seguir en los Kivus donde sacan importantes beneficios con los saqueos de recursos naturales (cf. Mercier, 2009) que retornar a Ruanda donde les esperan un futuro incierto, además de estar buscados muchos de sus jefes por la justicia internacional y por la justicia ruandesa por crímenes de guerra y crímenes de lesa humanidad. Están muy organizados y como señala Andrew (2010: 277), ni el APR (ejército ruandés), ni la AFDL de Kabila, ni el RCD/Goma, ni el CNDP de Nkunda han podido acabar con ellos, a pesar de sufrir importantes bajas con las últimas operaciones militares conjuntas de los ejércitos ruandés y congoleños con una balance muy controvertido ${ }^{4}$. Disponen de la colaboración de las milicias nacionalistas mayi mayi (procedentes de las etnias hutus congoleñas de los Kivu), cuyo objetivo es impedir la creación de un tutsilandia en la RDC.

- El CNDP liderado, hasta comienzos de 2009, por el general Nkunda, se presenta como el defensor de la población tutsi congoleña del Kivu contra los rebeldes hutus ruandeses o contra la ideología genocida y antitutsi de los FDLR. Su objetivo no declarado era conseguir la integración económica de la parte oriental de la RDC con Ruanda y Uganda, apostando por el federalismo o la descentralización.

4 Se trata de operaciones realizadas en colaboración con la MONUC, a la que sucedió, el 1 de julio de 2010, la MONUSCO (Misión de las Naciones Unidas para la Estabilización en el Congo), o en solitario contra las FDLR o los grupos rebeldes tanto en los Kivus, en Ituri y el en Bajo Uelé: operaciones Umoja Wetu, Kimya I y II, Amani Leo, «Pierre d'acier», Rudia, realizadas entre 2009 y 2011, y analizadas en otro espacio (cf. Kabunda, 2012: 224-226). 
Las diferentes mediaciones e iniciativas diplomáticas, internacionales (MONUC, UE) y africanas (UA, SADC), para evitar la regionalización de este nuevo conflicto, pasaban por alto las verdaderas causas del conflicto que son agrarias, políticas y económicas, así como el saqueo de los recursos naturales que lo alimentan, sobre todo en las provincias orientales de este país.

Las elecciones presidenciales y legislativas celebradas el 28 de noviembre de 2011, en un contexto de alta tensión y caracterizadas por «graves irregularidades y fraudes masivos» denunciados por los observadores internacionales, nacionales y la conferencia episcopal de este país (cf. Cros, 2012), acaban de consagrar la victoria a Joseph Kabila, convalidada por el Tribunal Superior de Justicia controlado por el poder. Con ello, se ha inaugurado otra etapa de inseguridad en este país, donde se planteará el problema de la legalidad y de la legitimidad del poder, dando alas a otros señores de la guerra, por la confiscación del poder, por un grupo, que ello va a suponer.

El problema del Congo, y sus consiguientes conflictos, es que constituye según Zartman (1990: 130), un «vacío atractivo» o «un espacio a mitad vacío», con una clase política corrupta y un ejército incompetente, y cuyos recursos, además de ser saqueados por las propias clases gobernantes congoleñas (Braeckman, 2009b), - que firmaron escandalosos contratos mineros y forestales con las multinacionales durante el gobierno de transición entre 2003 y $2006-$, alimentan la codicia de los países vecinos y las potencias externas con la consiguiente generalización de la violencia (cf. Kabunda, 2010). Es decir, la guerra en este país es deseada y mantenida, como queda subrayado, por todos los actores locales, regionales e internacionales, que sacan importantes beneficios de ella ${ }^{5}$, y por la vigente cultura de la impunidad y de la conspiración del silencio, que explica que muchos de los altos mandos en el poder en la región son responsables de crímenes políticos y económicos.

A pesar de la renuncia de Ntaganda, el jefe de las tropas del CNDP y su integración en las FARDC, y la detención de Nkunda en Ruanda, en enero de 2009, no se ha acabado con la inseguridad aún persistente en muchos territorios de la parte oriental de la RDC, que sigue siendo un santuario de los movimientos rebeldes de los países vecinos, y por lo tanto un polvorín. Este país, el $11^{\circ}$ Estado del mundo desde el punto de vista de la superficie (tras la partición de Sudán) y rodeado por nueve vecinos, es víctima del «dilema del centro»: el defenderse de los ataques procedentes de los países vecinos y al tiempo impedir el uso de su territorio en los ataques contra éstos, en un contexto hecho de inestabilidad con frecuentes alianzas y rupturas.

En definitiva, las guerras de los Grandes Lagos, en torno al Congo, se originan en las interacciones de las causas y actores locales, nacionales y regionales (Autessere, 2011), a partir de la politización de la etnicidad extrapolada a nivel regional entorno a la falsa y peligrosa dicotomización Bantú-Nilótico (Thakur, 2008), desembocando en lo que Jean Pierre-Chrétien califica de «etnicismo científico», que esconde las luchas por la tierra, los recursos y el poder.

5 Sin la previa reconstrucción y estabilización del Congo, tal y como manifestó el entonces presidente de Sudáfrica, Thabo Mbeki (cf. Braeckman, 2009b: 99), todos los proyectos panafricanos como el Nuevo Partenariado para el Desarrollo de África (NEPAD) o el «renacimiento africano», están condenados al fracaso o a no concretarse. Esta reconstrucción pasa según el informe de Dzinesa y Laker (2010: 9-10), por una batería de medidas y la implicación de varios actores regionales e internacionales. Se trata en lo esencial de: la construcción del aparato del Estado y su sistema judicial, la reinstauración de la democracia y la creación de una sociedad civil fuerte; la participación concertada y efectiva de las Naciones Unidas, la Unión Europea, la Unión Africana y la SADC, con la colaboración de Sudáfrica y Angola, en las operaciones de mantenimiento y reconstrucción de la paz, luchando contra la desestabilización regional y el saqueo de los recursos naturales de este país, etc. 


\section{Las guerras de Sudán: norte-sur y del Darfur}

Sudán (literalmente la tierra de los negros), - el hasta hace poco más grande Estado del continente desde el punto de vista de la superficie y con 42 millones de habitantes y 600 diferentes grupos étnicos-, fue un país dividido en dos realidades diametralmente opuestas: el norte musulmán y arabófono, orientado hacia el mundo árabe, y el sur animista y cristiano, incorporado en el África negra o subsahariana.

Este país vivió desde 1956 hasta 2005 una de las guerras más largas y sangrientas del continente entre el norte y el sur, con una tregua entre 1972 y 1982, consecuencia de los acuerdos de Addis Abeba que garantizaron diez años de paz y de amplia autonomía para el Sur.

Esta guerra nace fundamentalmente de la expansión árabe y musulmana hacia el sur, sometido a un proceso de etnocidio y de colonialismo interno con tinte racista y esclavista. Y desde febrero de 2003 hasta la actualidad, este país conoce otro conflicto con casi las mismas características que la anterior en su parte occidental, el Darfur. Analizamos ambas guerras a continuación.

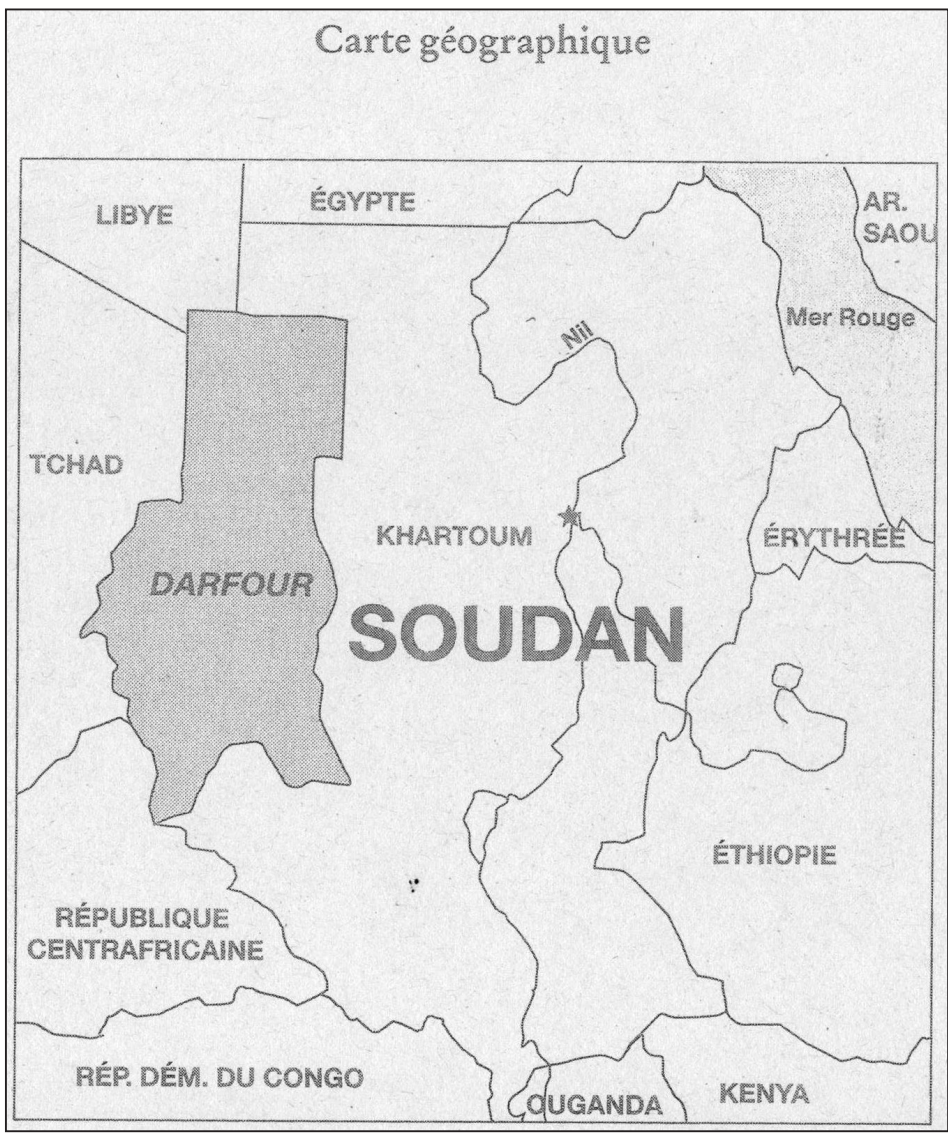

Figura 2. Mapa de Sudán y Darfur.

Fuente: www.mondialisation.ca 


\subsection{El conflicto entre el norte y el sur en Sudán}

La colonización británica llevó en Sudán una política de segregación racial y cultural entre el norte y el sur, para cambiar radicalmente a partir de 1947 mediante una política de unificación total del país. No se tomó ninguna precaución para proteger los intereses políticos, culturales y económicos de los pueblos del sur, confiando el poder a los árabes del norte. Ello pese al hecho que el sur empezó su rebelión unos meses antes de la independencia del país en 1956, mediante según subraya Owona (1985: 250), la masacre de sus oficiales árabes en Torit por las tropas de elite sureñas del contingente «Equatoria corps», el 18 de mayo de 1955, para reivindicar la autonomía del sur o la puesta bajo tutela de la ONU de las tres provincias de esta parte.

A pesar del mestizaje, cada grupo creó e intentó mantener su identidad. A ello cabe añadir el rechazo de los sucesivos gobiernos postcoloniales de Jartum de cumplir con las promesas federalistas hechas al sur, en 1956, a cambio de su aceptación de la independencia de un «Sudán unido».

Desde comienzos de la década de los 80 hasta 2005, el conflicto de Sudán se reanudó tras la mencionada tregua de diez años como consecuencia de la imposición de la sharia (o la ley islámica) por el presidente Gaafar el-Numeiri. Se había cobrado al menos 1,5 millones de muertos. Fue una verdadera pesadilla para las poblaciones del sur donde vivían 8 de los 26 millones de sudaneses, además de las numerosas víctimas de las guerras interétnicas entre los distintos grupos nilóticos de la parte meridional (medio millón de muertos), fomentadas por Jartum y por las viejas rivalidades ancestrales.

El conflicto entre el norte y el sur de Sudán tuvo distintas facetas o dimensiones siguientes:

- Colonial: el desarrollo desigual o separado entre ambas partes (la construcción de infraestructuras en el norte y el abandono total del sur dejado en manos de los misioneros cristianos) por la colonización británica, que introdujo los gérmenes de la guerra por su decisión de incorporar a los no musulmanes nilóticos y bantúes en una única entidad política dominada por el norte musulmán (Copson, 1994; Melville, 2002).

- Confesional y racial: la lucha entre cristianos-animistas y musulmanes, y entre árabes y negroafricanos.

- Política: la negación y la exclusión oficiales de las poblaciones del sur, consideradas como sin cultura y sin civilización. Es decir, como «inferiores», «infieles»y «primitivos», y a las que se deben aplicar la arabización y la islamización. A ello es preciso añadir la negación por las elites gubernamentales de las injusticias sociales y de la discriminación racial (cf. Abdel y de Waal, 2001) hacia algunos grupos del país.

- Económica: el descubrimiento del petróleo en la provincia sureña del Alto Nilo, en la década de los 70, fortaleció las aspiraciones secesionistas de las elites del sur y las tendencias centralistas del gobierno, para apoderarse de las riquezas del sur, junto a las codicias de las potencias externas para controlarlas.

El gobierno islamista de Omar al-Bashir, que sucedió al gobierno de Numeiri, estaba decidido a seguir con la guerra que le permitió movilizar al ejército en el sur y desviarlo de los graves problemas económicos y políticos internos, al mismo tiempo movilizaba socialmente a la juventud, desocupada y adoctrinada, y a la población norteña en torno a la idea de una yihad legítima contra los cristianos y paganos del sur y de los montes Nuba. El gobierno de Jartum fomentó incluso los conflictos interétnicos en el sur en el marco de la política de divide y vencerás. 
La rebelión del sur, encabezada en una primera etapa, o en la década de los 60, por la guerrilla de los Anya-Nya (del nombre de una planta tremendamente venenosa) y después por el Ejército Popular de Liberación de Sudán/Movimiento Popular de Liberación de Sudán (SPLA/SPLM), del coronel John Garang, siempre había planteado la separación del norte. Más tarde, Garang apostó por la igualdad, la justicia y la libertad en las relaciones entre el gobierno de Jartum y los demás pueblos y regiones de Sudán (el «nuevo Sudán» federal) en connivencia con los intereses de los gobiernos africanos (apegados al principio de la intangibilidad de las fronteras heredadas de la colonización), gobiernos que le suministraban armas y fondos para su guerrilla, en el caso particular de Etiopía y Uganda.

El balance de esta guerra, que duró más de cuarenta años, es escalofriante: el sur que tenía unos 8 millones de habitantes en el momento de la independencia (26 millones para todo el país), contó en el momento de la firma de los acuerdos de paz, en 2005, con sólo 4 millones. Cerca de dos millones habían muerto, un millón se refugió en los países vecinos (Etiopía, Kenia, Uganda, Chad y la RDC), un millón en el norte (donde fueron sometidos a un verdadero apartheid y dependiendo de la ayuda de las ONGs), y un millón en el propio sur en particular en Omdurman y los desiertos hostiles del Kordofan Norte, con una tasa de mortalidad infantil en torno al $50 \%$.

La independencia del sur era inevitable por el rechazo o el no reconocimiento por los sucesivos gobiernos centrales de la realidad multirracial, multiconfesional y multicultural o de la diversidad étnica de Sudán (cf. Abdel y de Waal, 2001), sometiendo a las poblaciones del sur (nuers y dinkas) a la política de arabización e islamización al considerar el cristianismo como una religión extranjera que debería ser limitado e incluso eliminado del país. El objetivo era crear un Sudán homogéneo o una nación islámica mediante un proyecto de asimilación del sur del país o la explotación, exclusión y transformación de los sudaneses negros sometidos a las organizaciones misioneras islamistas, y considerados como ciudadanos de segunda o tercera categoría que tenían que someterse a la «mayoría» árabe y musulmana del norte.

El Comprehensive Peace Agreement (CPA) - Acuerdo de Paz Global-, firmado el 9 de enero de 2005 en Nairobi, entre John Garang ${ }^{6}$ y el vicepresidente sudanés Ali Osman Mohamed al-Taha, fue el resultado de las presiones norteamericanas a ambos bandos: el gobierno de Jartum, que formaba parte de la lista de los «Estados canallas» norteamericana por su apoyo al terrorismo internacional mediante la colaboración con Al Qaida, no quiso exponerse a la invasión de Estados Unidos como sucedió con Irak7$^{7}$;

6 Tras la muerte de John Garang y en el marco del Comprehensive Peace Agreement - CPA - (o el Acuerdo de Paz Global), firmado en enero de 2005 entre el gobierno sudanés y el movimiento de rebelión del sur, Salva Kiir, el segundo de Garang, ocupó, además del puesto de vicepresidente en el gobierno central, las funciones de presidente del gobierno autónomo del sur y de líder del SPLA/M. Con el acceso a la independencia del Sur de Sudán en julio de 2011, es el jefe de Estado de la nueva República. Este acuerdo global fue precedido por los acuerdos firmados entre el norte y el sur (Machakos, julio de 2002, Naivasha, julio de 2004 y Nairobi, agosto de 2004), replantearon las bases del poder en Sudán al cuestionar la hasta entonces supremacía del norte en los aspectos políticos (nueva esquema de representación política), económicos (nuevos criterios de distribución de riquezas), militares (reorganización del Ejército) y religiosos o sociales (delimitación de los espacios de vigencia de la sharia y de las políticas de arabización).

7 La celebración del referéndum el 7 de enero de 2011 se explica también por el mandato de busca y captura de la Corte Penal Internacional (CPA), del 4 de marzo de 2009, contra el presidente Omar al-Bashir (relegido en abril de 2010 con el 68\% del sufragio), por los crímenes de guerra, crímenes de lesa humanidad y crímenes de genocidio cometidos en el Darfur. El mandatario sudanés debería dar este paso, como estrategia, para intentar escapar del mandato de la CPA. Tampoco se puede excluir una concesión de al-Bashir a los africanos por el rechazo de aplicar dicha sentencia por la Unión Africana en su cumbre celebrada en Sirte (Libia) en julio de 2009, expresando de este modo su solidaridad con el mandatario sudanés (salvo Botsuana), bajo la excusa de conseguir la paz en el sur de Sudán y en el Darfur. 
mientras que la rebelión del Movimiento/Ejército Popular para la Liberación de Sudán (SPLA/M) del coronel John Garang, debilitado por las disensiones internas y por la retirada del apoyo de Uganda, debería dar prioridad a la explotación del petróleo, ubicado en el sur del país, por los Estados Unidos que apoyaron indirectamente durante varias décadas su lucha de liberación.

El CPA previó en los cinco próximos años la celebración de un referéndum sobre la independencia del Sur de Sudán (enero de 2011) para decidir la población de esta parte la unidad con el norte o la separación (derecho a la autodeterminación); la creación de un gobierno de unión nacional con la conversión del SPLA/M en partido político; la institución de un gobierno autónomo del Sur de Sudán liderado por John Garang; la delimitación de la frontera de la región de Abyei - una región rica en petróleo, y mayoritariamente habitada por los dinkas, una etnia negroafricana-, entre el norte y el sur, remitiéndose a las fronteras de la época colonial; el reparto equitativo de los ingresos petroleros entre el gobierno central y el del sur de Sudán; y la retirada del ejército sudanés del sur, en julio de 2007, dejando el terreno al SPLM/A.

En este referéndum, el sur optó ampliamente (el 94\% del sufragio) por la independencia, y se convirtió en julio de 2011 en la República del Sur de Sudán, con Juba como capital, convirtiéndose en el $54^{\circ}$ Estado africano, y cuestionando hasta cierto punto el principio de la intangibilidad de las fronteras heredadas de la colonización, consagrado por la desaparecida Organización de la Unidad Africana (OUA) y confirmado por su sucesora, la Unión Africana.

La mencionada delimitación de la frontera entre el norte y el sur, prevista por el CPA, en torno a la región de Abyei (y también de los montes Nuba y el Nilo Azul), es un importante punto de fricción y tensión, ilustradas por los enfrentamientos recientes (diciembre de 2011 y enero y abril de 2012) entre el ejército de Jartum y el ejército del gobierno de Juba, máxime cuando esta región ubicada en el centro-sur de Sudán, se caracteriza por tener importantes yacimientos de petróleo ( 6 billones de reservas de barriles) y de capas acuíferas, además de las aguas del Nilo, que necesitan ambas partes. Es decir, estamos ante una zona estratégica y de importancia económica, que no está dispuesto a ceder el norte que hará todo para impedir la celebración de la consulta de la población de esta región, mayoritariamente negroafricana, como queda subrayado, para decidir su pertenencia al sur o al norte, con la consiguiente eventual reanudación de las contiendas como sucedió en diciembre de 2011 y en abril de 2012. Es preciso, por lo tanto, según sugieren Large y Saundres (2010), definir de una manera satisfactoria para ambas partes, las fronteras entre el norte y el sur en torno a la región de Abyei, y velar por la estabilidad del cuerno de África, del África Central y del África Oriental con importantes relaciones con el Sur de Sudán.

La independencia de Sudán del Sur, si pone fin a las pesadillas de la población de esta parte, - sometida durante siglos a la esclavitud, a la burla y al desprecio por ser considerados sus integrantes como ciudadanos de segundo rango (cf. Hussain, 2011) - , podría dar lugar, en la opinión de Omeje (2010), a un «frágil Estado rentista y autoritario» (al igual que algunos Estados subsaharianos como Nigeria, Gabón, Angola, Guinea Ecuatorial o la RDC) por depender casi exclusivamente del petróleo y por reunir todas las características para la confiscación del poder por el SPLM, a imagen de Eritrea, por acceder a la independencia fundamentalmente por la lucha armada liderada por este movimiento. Esta independencia podría inspirar, en un futuro cercano, las aspiraciones autonomistas de las otras periferias de este país (incluso en el propio norte) sometidas a la exclusión o marginación por el gobierno central, como en el caso de los montes Nuba o del Darfur, analizado a continuación. 


\subsection{Darfur o las contradicciones entre el centro y las periferias en Sudán}

El Darfur, situado en la región occidental semi-desértica de Sudán, en la intersección entre la zona de influencia británica y la zona de influencia francesa, entre el mar Rojo y el Mediterráneo, está poblado por 6 millones de personas distribuidas en tres estados dentro de Sudán (el Darfur septentrional, el Darfur meridional y el Darfur occidental): los fur (principalmente), los massalit, los zaghawas, los medob, los quran, los tunyur y una decena más de grupos menores. Es decir, un mosaico de agricultores y nómadas, todos musulmanes. Es el escenario, desde enero de 2003, de lo que algunos analistas de la zona calificaron de «primer genocidio del siglo XXI».

¿Cuáles son las motivaciones, declaradas o no, así como los principales protagonistas de este conflicto, y las eventuales salidas?

El conflicto entre el gobierno y dos grupos guerrilleros empezó a comienzos de 2003 cuando el Movimiento para la Liberación de Sudán (SLM) y el Movimiento por la Justicia y la Igualdad (JEM), - en reacción a la profunda situación de frustración nacida de la marginación de su región y del desprecio de las tribus del norte del país hacia su provincia particularmente afectada por la crisis económica que las demás provincias sudanesas - , atacaron a las tropas gubernamentales en el Darfur. Se trata, pues, fundamentalmente, de una rebelión o protesta contra la injusticia que de un movimiento separatista.

Aquellos movimientos rebeldes o de guerrilla se inspiraron en los acuerdos firmados entre el norte y el sur, para exigir la autonomía de su región, partiendo de la realidad según la cual no puede haber la paz global en Sudán sin paz en el Darfur, pues los acuerdos de Nairobi, de enero de 2005, pasaron por alto la cuestión del Darfur por la obsesión de las grandes potencias en poner fin a los 20 años de guerra entre el gobierno de Jartum y la rebelión del sur. Por lo tanto, los rebeldes del Darfur se inspiraron en estos acuerdos, para exigir también el fin de la marginación de su territorio y para combatir la arabización y la opresión a las que están siendo sometidos.

El gobierno de Jartum, que dispuso entonces de importantes medios militares tras el fin de la guerra con el sur, concentró lo esencial de sus fuerzas de destrucción y represión en el Darfur, para aplastar la rebelión iniciada en esta zona. El objetivo era evitar el efecto dominó de las reivindicaciones de autonomía en otras regiones del país marginadas por el gobierno central, y mantener la dominación de los «árabes» sobre los negros (cristianos o musulmanes).

El gobierno armó y financió las milicias locales o «árabes», los janjawids («los caballeros del diablo»), que respondieron con una violencia inusual a los ataques de aquellos movimientos, tanto en los medios utilizados como en el número de víctimas por las represalias en las aldeas de civiles de los tres estados del Darfur y en los campos de refugiados ubicados en Chad y Centroáfrica, sometidos a bombardeos y a las humillaciones con el uso de la violencia sexual como arma de guerra, siendo el objetivo «la eliminación de los negros», tachados peyorativamente de «zurga». Según denuncia Ziegler (2008), quien abunda en el mismo sentido, hombres, mujeres y niños pertenecientes a los massalit, fur y zaghawa son sometidos a los bombardeos de los Antonov y a los ataques terrestres de los janjawids, bajo las órdenes de los generales del ejército del gobierno islamista de Jartum. Es decir, las mismas prácticas que utilizó el gobierno, a través de los baggaras árabes y los pastores fellatas, contra los dinkas - reducidos a la esclavitud, al etnocidio y a los trabajos domésticos en los hogares árabes del norte y de Jartum-, durante la segunda guerra de Sudán entre el norte y el sur, en toda la década de los 80 , que coincide con el mandato de Gaafar el-Numeiri (cf. Madut Jok, 2001: 112-132). 
Dicho sea de paso que los propios darfuríes, negros y musulmanes, fueron utilizados en el pasado reciente por el gobierno central en la guerra contra los sureños, negros y no musulmanes, en nombre de la yihad contra los infieles.

Algunos autores hablan de «genocidio», y otros de crímenes de guerra por existir, según ellos, ninguna intención por parte del gobierno de Jartúm de eliminar a un grupo determinado. Lo cierto, según puntualiza Ibrahim (2008), es que el número de muertos, heridos y desplazados en el Darfur iguala el de las víctimas de la segunda guerra del Sudán, entre el gobierno y el sur del país, en su segunda etapa entre 1983 y 2005.

A diferencia del sur de Sudán, integrado exclusivamente por poblaciones animistas y cristianas, en el conflicto del Darfur, tanto los verdugos como sus víctimas, son negros y musulmanes, unos radicales y otros moderados. Aquellos, en su obsesión de convertirse en «árabes» (grupo superior) matan a otros negros. O como dice Prunier, «los negroafricanos matan a otros negroafricanos porque quieren ser árabes» (2007:54). Por lo tanto, no se trata de un conflicto confesional o una guerra de religión. Todos son musulmanes y negros: unos se consideran «árabes», y otros africanos. El autor mencionado habla al respecto de un «genocidio ambiguo» (cf. Prunier, 2005). La colaboración de grupos identificados como negros (chadianos o sudaneses) con los janjawids se explica por varias razones (Tubiana y Tanner, 2008: 309), entre ellas: su fuerte arabización, su identificación con el modo de vida árabe, su hostilidad contra los zaghawas y el miedo de ser atacados por los árabes o los janjawids o por tener intereses comunes con éstos y por ser atraídos por las ventajas materiales ofrecidas por el gobierno sudanés. Este último aspecto explica la presencia de muchos zaghawas entre los janjawids.

Antes que un conflicto entre árabes y negroafricanos, según puntualiza Debos (2007), la crisis del Darfur es ante todo política y nace del acceso al agua y de la gestión de la misma, junto a la marginación política y económica de esta región. En la opinión de Onana (2008; véase también a Nguyen, 2010), quien abunda en el mismo sentido, no se puede reducir el conflicto del Darfur a la única dimensión étnica y racial entre africanos y árabes, sino también a los aspectos políticos y ecológicos, en particular la sequía que afecta al norte y que empuja a los janjawids, que son también negros y musulmanes, a buscar el pasto y el agua en el Darfur mediante razias, dirigiendo sus ataques, según subraya Hagan y Rymond-Richmond (2009) hacia las etnias negras para adueñarse de sus tierras, limpiando áreas enteras de sus habitantes originales para convertirlas en regiones controladas por los «árabes».

Los acuerdos de Abuya (Nigeria), el Darfour Peace Agreement o los Acuerdos de Paz sobre el Darfur (APD), firmados el 5 de mayo de 2006 entre el gobierno de Jartum y el principal movimiento de rebelión del Darfur, el SLM de Minni Arku Minnawi (cooptado por el gobierno), y presidido por la UA, previó el desarme de los janjawids por el gobierno, antes de octubre de 2006, como base de la instauración de la paz y de la reconciliación. Sin embargo, estos acuerdos fueron rechazados por el JEM y la otra facción movimiento minoritario y disidente del SLM, dejando intactas las tensiones en la región con el riesgo de «somalización».

El APD que insiste en el desarme de los janjawids (incorporados en las fuerzas de seguridad oficiales) precedido por la retirada por los rebeldes de las zonas ocupadas, cometió según De Waal (2007), el error de siempre: el pasar por alto las causas históricas, estructurales, políticas, económicas y sociales del conflicto, que son complejas y profundas y en particular la marginación socioeconómica y política de las periferias, para atacarse sólo a los efectos y a las causas inmediatas sin la previa construcción o reinstauración de la confianza entre las partes. Lo que complica la resolución del conflicto del Darfur, es 
que según Large y Saunders (2010), tanto el gobierno de Jartum como el JEM y el SLM, apuestan por la solución militar ${ }^{8}$.

\section{Conclusión}

A la luz del análisis que antecedente, no cabe la menor duda que es el propio Estado africano que se encuentra en el origen o la fuente de los conflictos (cf. Copson, 1994). Éstos nacen de la crisis de la legitimidad de los Estados, convertidos en partes y jueces, y con ambiciones hegemónicas sobre sus sociedades y con prácticas de exclusión.

En el mismo sentido, Cilliers (1999) y Nagan (2002) recuerdan que se trata de unos Estados generalmente pobres, débiles, frágiles, inestables, predadores, en crisis de legitimidad permanente por no adaptarse al carácter multinacional de su sociedad, e incapaces de asumir las funciones de la soberanía y de suministrar los servicios básicos a la mayoría de la población.

Los conflictos que varían en cuanto a su intensidad, duración y extensión y pueden tomar una dimensión interna o regional con la implicación de redes internacionales, pero todos con una crueldad inédita, por las pugnas por recursos naturales, tal y como puede comprobarse en los principales focos de conflictos de las dos últimas décadas.

Aunque las razones de estos conflictos son múltiples: culturales, confesionales, políticas, militares, tienen cierta continuidad histórica y son avivados por el contexto de la escasez de las tierras y la crisis, es decir, no se limitan al único aspecto económico a pesar de tener un carácter depredador y de captación de rentas (Hugon, 2007).

Todo debe entrever que el marasmo económico que caracteriza al continente, junto al callejón sin salida al que ha conducido el proceso de democratización en algunos países, corre el riesgo de acentuar los conflictos económicos e identitarios (étnicos y confesionales), como consecuencia del derrumbe de la agricultura y la industria minera, que constituyen los dos pilares de las economías africanas. Los últimos acontecimientos sucedidos en Nigeria, en diciembre de 2011 y enero y abril de 2012, con los ataques mortíferos de las iglesias cristianas por las sectas fundamentalistas islamistas, son al respecto ilustrativos.

En fin, las guerras africanas que algunos medios de comunicación occidentales suelen tachar equivocadamente de «tribales» se originan en una serie de factores que van desde las desigualdades hasta la codicia por el control de los recursos naturales. Ello viene ilustrado por el caso de los conflictos del Congo donde los recursos naturales, en lugar de servir para la mejora de las pésimas condiciones de vida de la población, sirven paradójicamente para la financiación de las guerras, para la compra de armas en el mercado negro y para los intereses de las multinacionales; mientras que las guerras de Sudán nacen fundamentalmente del desarrollo desigual entre el centro y las periferias de este país (cf. Ylönen, 2012). Es decir, unas desigualdades (sociales, económicas, políticas y culturales, sobretodo, en los aspectos de desarrollo humano) que se remontan a la época de la colonización británica.

\section{Bibliografía}

ABDEL S. A. H. y DE WAAL A. - eds.- (2001): Phoenix State. Civil Society and the Future of Sudan. The Red Sea Press. Lawrenceville-Asmara, 308 pp.

8 En efecto, las rivalidades entre el liderazgo zaghawa (SLM/Minni) y el liderazgo fur (SLM/Abdelwahid) en el seno de la rebelión armada, conduce al gobierno a privilegiar la solución militar supuestamente por la falta de un interlocutor válido o fiable con el que se puede negociar. Ello viene ilustrado por la ofensiva militar del gobierno, a finales de diciembre de 2011 en el Kordofán del Norte, que terminó con la muerte de Khalil Ibrahim, el líder del JEM, uno de los grupos más organizados y combativos de la rebelión. 
ANDREW S. S. (2010): Laurent Nkunda et la rebellion du Kivu. Au Coeur de la guerre congolaise. Karthala. París, 336 pp.

AUTESSERE S. (2011): «The trouble with the Congo: a préécis», en African Security Review 20:2, Londres, pp. 56-65.

AYAD C. (2008):»Rwanda: l'enquête relancée en France», Libération del 19 de noviembre, París, pp. 2-3.

AYAD C. y BERNARD PH. (2012): «Rwanda, une passion française», Le Monde del 27 de enero, París, pp. 22-33.

BRAECKMAN C. (2009a): Les nouveaux prédateurs. Politique des puissances en Afrique centrale ( $2^{\mathrm{a}}$ edición). Éditions Aden. Bruselas, 397 pp.

BRAECKMAN C. (2009b): Vers la deuxième indépendance du Congo. Le Cri-édition-Afrique Éditions. Bruselas-Kinshasa, 267pp.

CILLIERS J. (1999): «Regional African Peacekeeping Capacity-Mythical Constructor Essential Tool?», en From Peacemaking to Complex Emergencies. Peace Support Missions in Africa (Jakkie Cilliers y Greg Mills), The South African Institute of International Affairs-The Institute for Security Studies, Johanesburgo-Pretoria, pp. 133-152.

COPSON R.W. (1994): Africans Wars and Prospects for Peace. M.E Sharpe. Nueva York-Londres, $211 \mathrm{pp}$.

CROS M-F. (2012): «Et maintenant où va le Congo?», www.lalibre.be/actu/international/article/716101/et-maintenant-ou-va-le-congo.html

DE WAAL A. (2007): War in Darfur and the search for peace. The Social Science Research Council. Londres, 431pp.

DEBOS M. (2007): «Darfour, Tchad, RCA. Le développement d'une crise régionale», en Ramses 2008. IFRI-DUNOD. París, pp. 269-273.

DEL PONTE C. (2009) -en colaboración con Chuck Sudevic-: La traque, les criminels de guerre et moi (traducción del inglés de Isabelle Taudière). Éditions Héloïse d'Ormesson. Mayenne, 649 pp.

DZINESA G. y LAKER J. (rapporteurs) (2010): Post-Conflict Reconstruction in the Democratic Republic (DRC). Advisory Group Seminar Report (Centre for Conflict Resolution). Ciudad del Cabo, abril, 56pp.

FLINT J. y DE WAAL A. (2007): Darfur. Historia de una larga guerra (traducción de Ana Isabel González). Intermón-Oxfam. Barcelona,128 pp.

HAGAN J. y RYMOND-RICHMOND W. (2009): Darfur and the Crime of Genocide. Cambridge University Press. 2009, 269 pp.

HIRSCH J.L. (2001): Sierra Leona. Diamonds and the Struggle for Democracy. International Peace Academy Occasional Paper Series-Lynne Rienner Publishers. Londres, 175 pp.

HUGON PH. (2007): Géopolitique de l' Afrique. Éditions Sedes. París, 239 pp.

HUSSAIN L. (2011): «El problema está en la tribu: el caso de Sudán», en Cuadernos Africanos, Casa África, Las Palmas de Gran Canaria, septiembre, pp. 57-61.

IBRAHIM H. (2005): «Darfour: brouet de sang», en Outre Terre $\mathrm{n}^{\circ} 11$ (Revue française de géopolitique ). OGRE-Éditions érès. París, pp. 405-409.

KABUNDA M. (1997): «Conexiones (inter) nacionales y dinámicas regionales en la crisis africana de los Grandes Lagos», en Escenarios de la globalización (ed: Francisco Jarauta), Caja Murcia, Murcia, pp. 69-108.

KABUNDA M. (2010): «Causas y efectos de la conflictividad en la República Democrática del Congo y los Grandes Lagos», en Papeles de relaciones ecosociales y cambio social $\mathrm{n}^{\circ} 110$. Madrid, pp. 133-144.

KABUNDA M. (2012): «Los conflictos de la República Democrática del Congo en el contexto de la región de los Grandes Lagos», en Más allá de la barbarie y la codicia. Historia y política en las guerras africanas (ed: Itziar Ruiz-Giménez Arrieta). Edicions Bellaterra, Barcelona, pp. 201-245.

KLARE M.T. (2003): Guerras por los recursos. El futuro escenario del conflicto global (traducción de J. A. Bravo). Ediciones Uranio. Barcelona, 345 pp.

LARGE D. y SAUNDERS C. (2010): Stabilising Sudan: Domestic, Sub-Regional, and Extra-Regional Challenges. Advisory Group Seminar Report (Centre for Conflict Resolution). Ciudad del Cabo, agosto, $52 \mathrm{pp}$. 
MADUT J. J. (2001): War and Slavery in Sudan, University of Pennsylvania Press, Filadelfia, 224pp.

MELVILL D. (2002): Restoring peace and democracy in Sudan: limited choice for African leadership, IGD Occasional Paper $\mathrm{n}^{\circ} 34$, Braamfontein, noviembre, $35 \mathrm{pp}$.

MERCIER B. (2009): RD Congo. Ressources naturelles et violences. Le cas des FDLR. Rapport du GRIP ${ }^{\circ} 7$. Bruselas, 24 pp.

MISSER F. y VALLÉE O. (1997): Les Gemmocraties, l'économie politique du diamant africain. Desclée de Brower. París, 243 pp.

NABUDERE D.W. (2003): «Conflict war mineral wealth: understanding the second invasion of the DRC», Occasional Paper no 37, Institute for Global Dialogue, Pretoria, septiembre, pp. 40-66.

NAGAN W.P. (2002): «Post-Conflict Governance: Preventing Future Conflict and Ensuring Development», en Charting a new Course. Globalisation, African Recovery and the New Africa Initiative (eds: Richard Gibb et al), The South African Institute of International Affairs, Johanesburgo, pp. 67-89.

NAIDOO S. (2003): «Ending the war economy in the DRC», Occasional Paper $n^{\circ}$ 37, Institute for Global Dialogue, Pretoria, septiembre, pp. 85-91.

NGUYEN E. (2010): Géopolitique de l'Afrique. Du continent noir oublié à la renaissance africaine. Studyrama. Lévallois-Perret, 233pp.

OMEJE K. (2010): Dangers of splitting a fragile rentier state: Getting it right in Southern Soudan, Occasional Paper Series, ACCORD, Umlhanga Rocks, pp. 32.

ONANA C. - ed.- (2005): Silence sur un attentat. Le scandale du génocide ruandais. Editions Duboiris. París.117pp.

OWONA J. (1985): Droit constitutionnel et régimes politiques africains. Berger-Levrault. París, 410 pp.

PÉRIÈS G. y SERVENAY D. (2007): Une guerre noire. Enquête sur les origines du génocide rwandais (1959-1994). La Découverte. París, 414pp.

POURTIER R. (2004): «Afrique des Grands Lacs-Congo: la guerre est-elle fatale?», en Questions Internationales $\mathrm{n}^{\circ}$ 5, París, enero-febrero, pp. 32-34.

PRUNIER G. (2005): Darfur. The Ambiguous Genocide. Hurst and Company. Londres, 212 pp.

PRUNIER G. (2007): «Un genocide ambigu», en Urgence Darfour (dir: Morad El Hattab), Des Idées et des Hommes, Paris, pp. 43-46.

RAMBOTHAM O. et al (2011): Resolución de conflictos. La prevención, gestión y transformación de conflictos letales. Institut Català Internacional per la Pau. Barcelona, 604 pp.

ROTHCHILD D. (1997): Managing Ethnic Conflict in Africa. Pressures and Incentives for Cooperation. Brookings Institution Press. Washington, $343 \mathrm{pp}$.

THAKUR M. (2008): «Demilitarising militias in the Kivus (eastern Democratic Republic of Congo», en-AUTESSERE S. (2011): «The trouble with the Congo: a précis», en African Security Review 17:1, Londres, pp. 51-67.

TUBIANA J. y TANNER V. (2008): «Au Tchad, un second Darfour?» en Outre Terre n ${ }^{\circ} 20$ (Revue française de géopolitique), OGENI-Éditions érès, París, pp. 301-315.

UWIZEYIMANA L. (2005): «L'État: territoire, identité, acteur du développement?», en L'Afrique. Continent pluriel (dir: François Bart), CNED-SEDES, París, pp. 109-129.

WILLAME J-C. (2007): Les faiseurs de paix au Congo. Gestion d'une crise internationale dans un Etat sous tutelle. GRIP. Bruselas, 217 pp.

YLÖNEN A. (2012): «Sudán: el estado marginalizador y desafíos desde las periferias», en Más allá de la barbarie y la codicia. Historia y política en las guerras africanas (ed : Itziar Ruiz-Giménez Arrieta). Edicions Bellaterra, Barcelona, pp. 285-322.

ZARTMAN W.J. (1990): La résolution des conflits en Afrique (traducción de M.C.Gamberini y del autor). L'Harmattan. París, 269 pp.

ZIEGLER J. (2008): La haine de l'Occident. Albin Michel. París, 302 pp. 